積雪の圧密性を考慮した積雪深変化に関する研究 Study on snow depth change taking account of consolidation effect of snow

(株) 大東設計コンサルタント 正 員○村 上龍 東京理科大学理工学部

正員大西外明

1. はじめに

融雪流出量の計算方法扔よび解析結果は今まで幾つか報告されて扔り、融雪流出量と実泪流出量との比較 検討については、タンクモデル，貯留関数等の流出モデルに組込まれて解析されてきているが、直接的に積 雪からの融雪流出量と実測瀜雪流出量との比較検討はあまり行なわれていない。その理由としては、現地に 扔いて融雪量を直接的に測定することは困難であり、その結果、現地観測資料はほとんどみられないからだ と考えられる。このようなことから、本論文では、実測融雪量に代わるものとして現地観測が行ないやすく、 そして、現地観測資料が整理されている実測積雪哚変化を用いて、積雪深変化の解析值と実測値とを比較検 討することにより、虽雪量の重要な要因であると考えられる気温日融雪率を決定することを目的とするすの である。それとともに、積雪層内の構成状況の解析も行なう。

\title{
2. 積雪の圧密性を考虑した積雪深変化の計算方法
}

前報の水理講演会に怙いて、多雪地带の皘雪深変化を従来の考え方による方法と $\mathrm{A} ・ \mathrm{~F} ・ \mathrm{D}$ 型皘雪モデルに よる方法とにより実测積雪深との比較検討を行なった。その結果、従来の考え方による雪の比重が 1 つの場 合と比較して、降雪比重と積雪比重の 2 つを用いた A・F・D 型皘雪モデルの方がより実測皘雪深に近いこと が認められたが、皘雪の圧密効果を導入していないため、積雪深変化の解析値と実測値の間に十分な一致が 認められなかった。また、従来の積雪計算扣よび $\mathrm{A} ・ \mathrm{~F} ・ \mathrm{D}$ 型積雪モデルでは、初期皘雪深が安定した時期（ 1 月初旬頃）から計算すると全体的に実測皘雪深に合ってくるが、降雪が始まる時期（1 12 月初旬頃）から 計算を開始すると皘雪潹変化が全体的に小さく出てくる。このような問題を解 明するため、今回の研究では $\mathrm{A} ・ \mathrm{~F} ・ \mathrm{D}$ 型積雪モデルを発展させて、皘雪の圧密性を考慮した積雪深変化の計算方法を作成した。以下にこ の計算の考え方について述べる。

(1) 計算に必要な条件

計算方法を述べる前に皘雪・融雪を構成する計算条件について述べる。

（a）皘雪が生じる条件：(1) 気温 $\mathrm{t}<0 \mathrm{C}$ で降雪のみ皘雪し、降雨は皘雪せず流出する。(2) 気温 $\mathrm{t}<0 \mathrm{C}$ で降雪・降雨ともに皘雪となる。計算は、この1 ，(2) 2 ケースについてそれぞれ行なうものとする。な招 $\mathrm{A} \cdot \mathrm{F} ・ \mathrm{D}$ 型積雪モデルでは、(1の考え方により計算を行なった。

(b) 融雪が生じる条件：(1) 気温が $1 \mathrm{C}$ 上昇する毎に生じる融雪量（気温日融雪率=0.7 8.9 mm/ c ・ d a y )。

(2) 降雨から供給される熱量によって生じる融雪量。融雪が生じる条件は、この1)，(2の条件のみと考兄、 地熱等による虽雪は無視するものとする。これらから、積雪変化深は、皘雪水量の発生と融雪水量の発生に よる両者の相互関係から構成されることになる。

（c）皘雪の圧密条件：(1) (a)の(1)の場合について、降雪比重から積雪比重へ压密が進行する期間を10 日間 と仮定し、それ以後は一定比重で王密が進行すると考える。(2)（a)の(2)の場合について、降雪については、

(a) と(1) と同様に压密されて雪が締め固まってゆくと考兄、降雨が積雪となる場合は、かなり比重の高い雪と 考兄、一定比重で皘雪になると仮定する。ここで、(1)，(2)の計算值と実測值の雪溶け日が一致する必要があ り、その大きな要因として次の条件が考学られる。

（d）雪溶け日が一致する条件：(1) 降雪比重により降雪水量を調節する。(2) 気温による融雪定数により虽 
雪水量を調節する。ここで、降雨から供給される熱量による融雪水量は変化しないものとする。

（2）皘雪の圧密性を考慮した積雪哚変化の計算方法

(1) 皘雪の圧密比重の求め方

皘雪の压密比重は、降雪比重から最終圧密比重まで直線 変化すると仮定し、それ以後は一定最終圧密比重で進行す るものとする。

$$
\begin{aligned}
\rho(\mathrm{L}) & =\rho_{\mathrm{o}}+\mathrm{d} \rho \times(\mathrm{L}-1) \\
\mathrm{d} \rho & =\frac{\rho f-\rho_{\mathrm{o}}}{\mathrm{L} f}
\end{aligned}
$$

$\rho(\mathrm{L}):$ 皘雪圧密比重 $\quad \rho_{\mathrm{o}}$ : 降雪比重

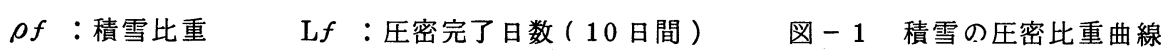

（2) 皘雪深と皘雪水量の圧密過程の考方方

降雪がある場合、降雪深から皘雪深に至るまでの圧密過程を困ー 2 に示し、それに対応する積雪水量の日 的変化を図 -3 に示す。

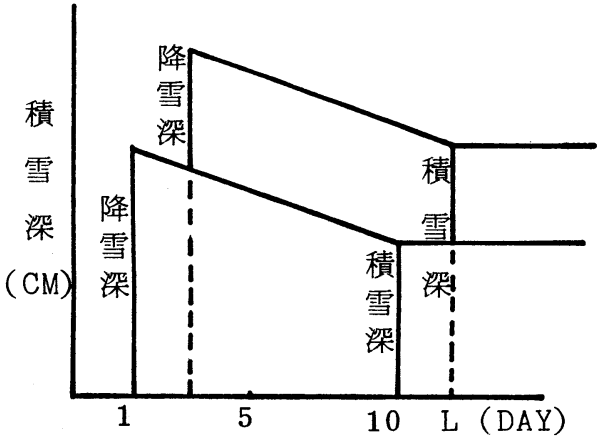

図 -2 積雪潹圧密過程図

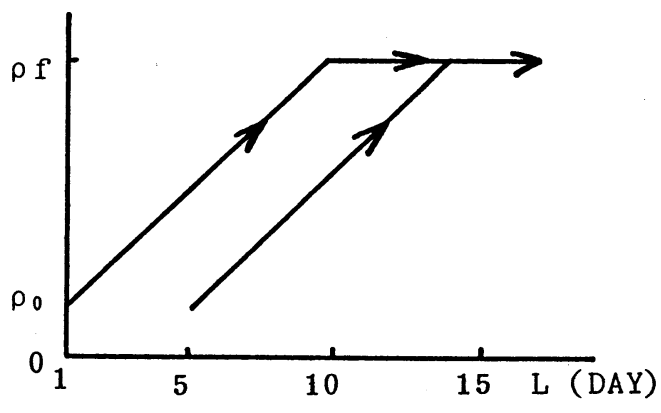

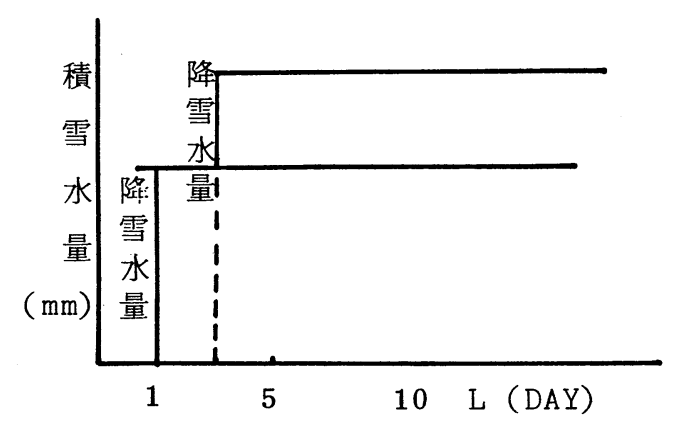

図 -3 積雪水量変化図

\section{(3) 各層每の皘雪深扔よび皘雪水量の計算方法}

各層毎の皘雪水量抽よび皘雪深の計算方法について以下に示す。図ー4は、各層毎の皘雪潹変化図を示し、 図ー5 は各首每の皘雪水量の変化図を示している。また、図ー6 4 計算例として 4 日目の压密過程を例にと り上げて、皘雪層断面の皘雪深と虽雪の考え方を示したものであり、図ー 7 は図ー 6 と同様に積雪水量と融 雪水量の考え方を示す。

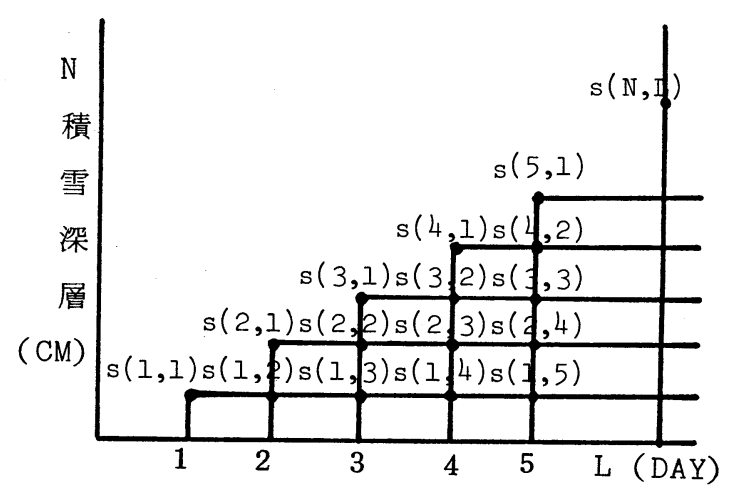

図 -4 各層毎の皘雪深変化図

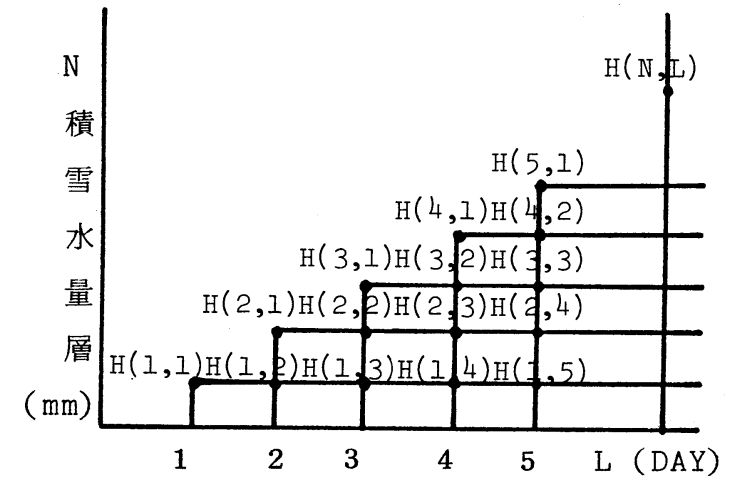

図 5 各層毎の積雪水量変化図 


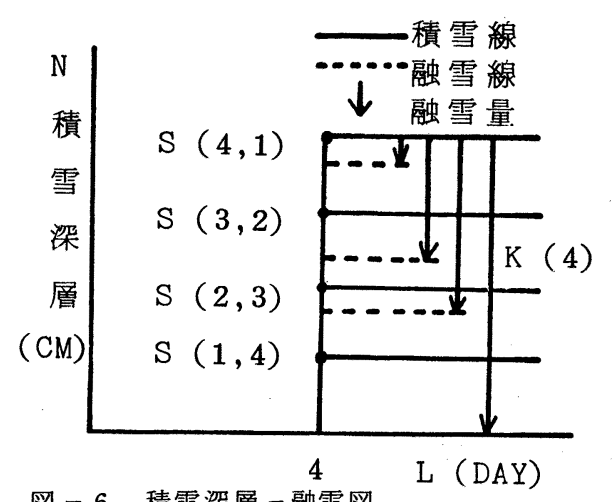

図 - 6 積雪深層. 一融雪図

$$
\mathrm{k}=\mathrm{k}_{1}+\mathrm{k}_{2}, \mathrm{k}_{1}=\mathrm{t} \times \mathrm{kt}, \mathrm{k}_{2}=\mathrm{rt} / 80
$$

ここで、上図の記号は次のようである。

$\mathrm{L}$ ：計算期間， $\mathrm{N}$ ：積雪層番号

$\mathrm{H}(\mathrm{N}, \mathrm{L})$ : 各層毎の積雪水量 $(\mathrm{mm})$

$\mathrm{S}(\mathrm{N}, \mathrm{L})$ : 各層毎の積雪潹 $(\mathrm{cm})$

S S ( L ) : 層断面を合計した積雪深 $(\mathrm{cm})$

$\Sigma \mathrm{H}(\mathrm{L})$ : 層断面を合計した積雪水量（mm）

$\mathrm{k}(\mathrm{L})$ : 融雪水量 $(\mathrm{mm})$

$$
\mathrm{k}_{1}: \text { 気温による融雪水量 }(m m)
$$

$\mathrm{k}_{2}$ : 降雨による融雪水量 $(\mathrm{mm})$

$\mathrm{k} \mathrm{t}$ : 気温日融雪率, $\mathrm{t}:$ 気温 $(\mathrm{C}), \mathrm{r}$ : 降雨量 $(\mathrm{mm})$ 図 -8 首断面の合計積雪深

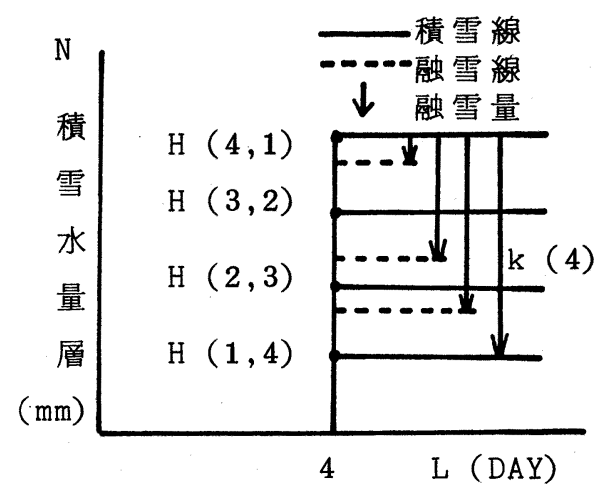

図 -7 積雪水量 一融雪水量図

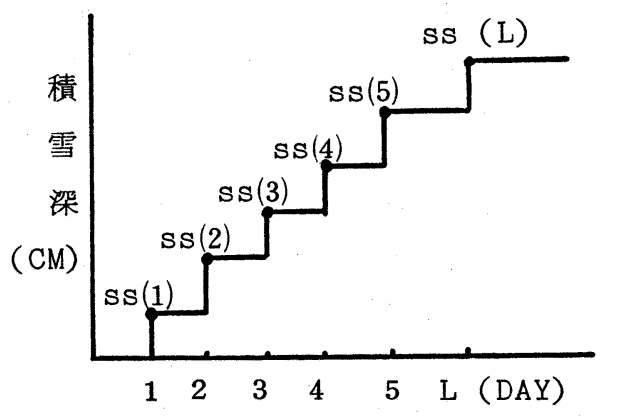

（）各層毎の積雪水量の計算方法

図ー7に示されるように、計算期間として 4 日目を例にとり上げて各層毎の積雪水量の計算方法を以下に 示す。

(i) $\mathrm{k}(4)<\mathrm{H}(4,1) の$ 場合 $\Sigma \mathrm{H}(4)=\mathrm{H}(1,4)+\mathrm{H}(2,3)+\mathrm{H}(3,2)-(\mathrm{k}(4)-\mathrm{H}(4,1))$

(ii) $\mathrm{k}(4)<\mathrm{H}(4,1)+\mathrm{H}(3,2)$ の場合 $\Sigma \mathrm{H}(4)=\mathrm{H}(1,4)+\mathrm{H}(2,3)-(\mathrm{k}(4)-\mathrm{H}(3,2)-\mathrm{H}(4,1))$

(iii) $\mathrm{k}(4)<\mathrm{H}(4,1)+\mathrm{H}(3,2)+\mathrm{H}(2,3)$ の場合 $\Sigma \mathrm{H}(4)=\mathrm{H}(1,4)-(\mathrm{k}(4)-\mathrm{H}(2,3)-\mathrm{H}(3,2)-\mathrm{H}(4,1))$

(v) $\mathrm{H}(4,1)+\mathrm{H}(3,2)+\mathrm{H}(2,3)+\mathrm{H}(1,4)<\mathrm{k}(4)$ の場合 $\Sigma \mathrm{H}(4)=0$

(口) 各層毎の積雪潹の計算方法

(1)で計算された積雪水量を圧密比重から積雪深に換算する計算であり、以下にその方法を示す。（図一6 参照 )

(i) $\mathrm{K}(4)<\mathrm{S}(4,1)$ の場合

$\mathrm{S} \mathrm{S}(4)=\mathrm{S}(1,4)+\mathrm{S}(2,3)+\mathrm{S}(3,2)+\frac{\mathrm{H}(4,1)-\mathrm{k}(4)}{\rho(1) \times 10}$

(ii) $\mathrm{K}(4)<\mathrm{S}(4,1)+\mathrm{S}(3,2)$ の場合

$\mathrm{S} \mathrm{S}(4)=\mathrm{S}(1,4)+\mathrm{S}(2,3)+\frac{\mathrm{H}(4,1)+\mathrm{H}(3,2)-\mathrm{k}(4)}{\rho(2) \times 10}$ 
(iii) $\mathrm{K}(4)<\mathrm{S}(4,1)+\mathrm{S}(2,3)$ の場合

$\mathrm{S} \mathrm{S}(4)=\mathrm{S}(1,4)+\frac{\mathrm{H}(4,1)+\mathrm{H}(3,2)+\mathrm{H}(2,3)-\mathrm{k}(4)}{\rho(3) \times 10}$

(V) $\mathrm{s}(4,1)+\mathrm{S}(3,2)+\mathrm{s}(2,3)+\mathrm{s}(1,4)<\mathrm{k}(4)$ の場合 $\mathrm{S} \mathrm{S}(4)=0$

計算方法として、計算期間 4 日目を例にとり上げて述へてきたが、上述の考え方にしたがって、積雪・瀜 雪期間までの計算を行なっていく。この考方は、(a)の@の条件で述べた気温 $\mathrm{t}<0 \mathrm{C} て ゙$ 降雪のみ積雪とな る場合であり、(a)の(2の条件では、上述の考え方に新たに降雨比重が付け加わる。

\section{3. 解析結果と考察}

計算に用いた資料は、前報の水講で用いた奥只見夕ム流域の水文観測資料を使用した。対象とした計算期 間は、1977 年〜 1981 年の 4 ケ年について積雪深変化の計算を行なった。計算ケースとしては、前述した ように次の 2 ケースの考え方について 4 年間の計算を行なった。

(1) Case 1 : 気温 $\mathrm{t}<0 \mathrm{C}$ で降雪のみ積雪し、降雨は流出する。

(2) Case 2 : 気温 $\mathrm{t}<0 \mathrm{C}$ で降雪・降雨ともに積雪となる。

これらの計算結果から気温による融雪定数が融雪期にどのような影響を与えるかを明らかにし、積雪深変 化を実測值と比較検討することにより気温日融雪率の値を試算することにより定めた。

最初に図ー9に従来の方法による積雪深変化と A・F・D 型皘雪モデルによる積雪深変化を示す。この計算 で用いた雪の比重, 気温日融雪率は次のようである。

（i）従来の方法による皘雪潹変化

0 雪の比重 $=0.45$

$\mathrm{o}$ 気温日融雪率 $=5.0 \mathrm{~mm} / \mathrm{C} \cdot \mathrm{d}$ a y

(ii) $\mathrm{A} ・ \mathrm{~F} ・ \mathrm{D}$ 型皘雪モデルによる積雪深変化

0 降雪比重 $=0.05$

0 積雪比重 $=0.45$

0 気温日融雪率 $=5.0 \mathrm{~mm} / \mathrm{C} \cdot \mathrm{d}$ a y

次に、積雪の圧密性を考慮した積雪深変化につい て計算した結果を図一 10 （c a s e 1，1978年）、 図一1 (case 2,1978年), 図-12(case 1 1979 年), 図一 13 (case 2, 1979 年) に示す。 そして、1977 年 1981 年の 4 年間の計算結果か ら得られた雪の比重, 気温日融雪率を表一 1 にまと めて表わす。

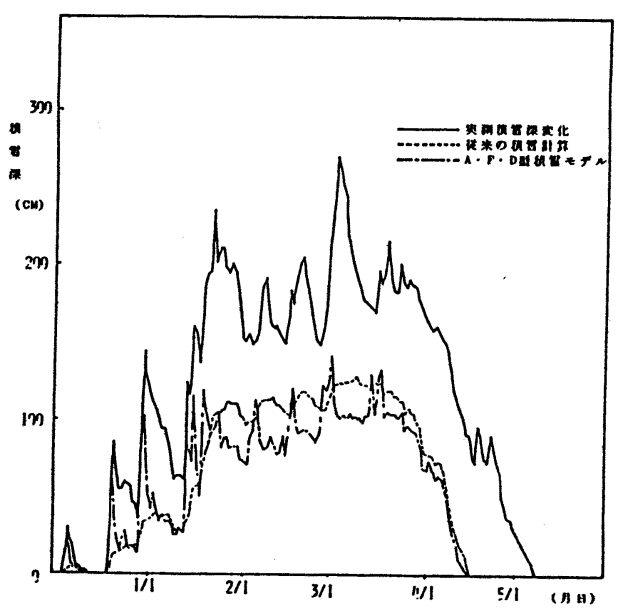

図 -9 従来の方法と $\mathrm{A} \cdot \mathrm{F} \cdot \mathrm{D}$ 型積雪モデル による皘雪深変化図 (1978年12月〜 1979 年 6 月)

表一 $1 \quad 1977$ 年 1981 年の計算定数一覧表

\begin{tabular}{|c|c|c|c|c|c|c|c|}
\hline 計算定数 & \multicolumn{3}{|c|}{ c a $s$ e 1} & \multicolumn{4}{|c|}{ c a $s$ e 2} \\
\hline 計算対象年 & 降雪比重 & 積雪比重 & 気温日融雪率 & 降雪比重 & 積雪比重 & 降雨比童 & 気温日融雪率 \\
\hline 1977 年 12 月 1978 年 6 月 & 0.075 & 0.5 & 4.5 & 0.05 & 0.5 & 0.75 & 6.5 \\
\hline 1978 年 12 月〜 1979 年 6 月 & 0.075 & 0.5 & 4.5 & 0.05 & 0.5 & 0.75 & 5.5 \\
\hline 1979 年 12 月〜 1980 年 6 月 & 0.075 & 0.5 & 5.5 & 0.05 & 0.5 & 0.75 & 6.5 \\
\hline 1980 年 12 月 1981 年 6 月 & 0.075 & 0.5 & 5.5 & 0.05 & 0.5 & 0.75 & 6.5 \\
\hline
\end{tabular}




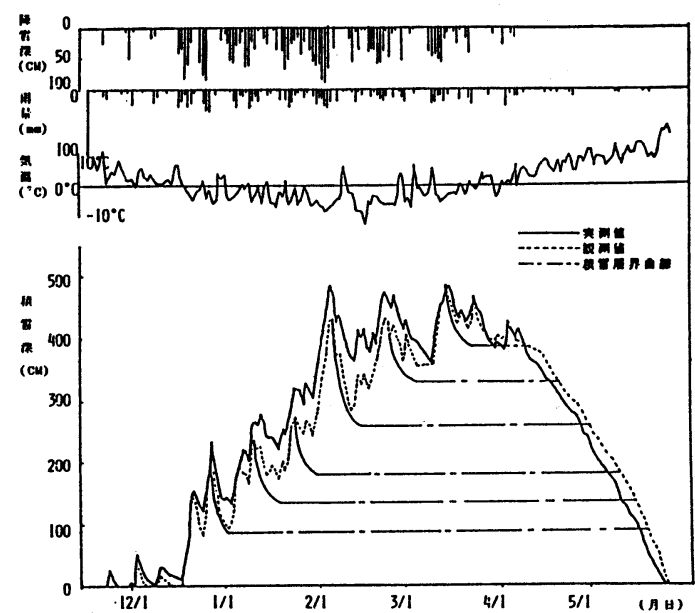

困 - 10 積雪深変化図 ( c a s e 1 ,

1977 年 12 月 1978 年 6 月)
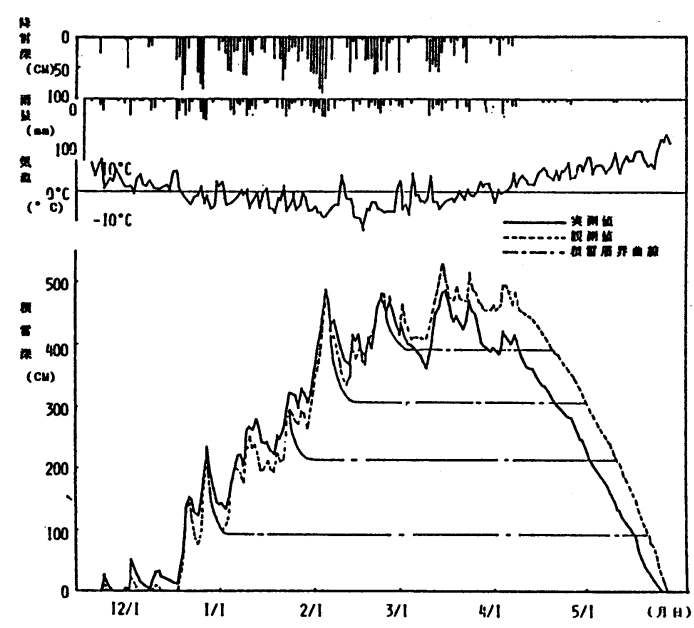

図 - 11 積雪深変化図 ( c a s e 2,

1977 年 12 月 1978 年 6 月)

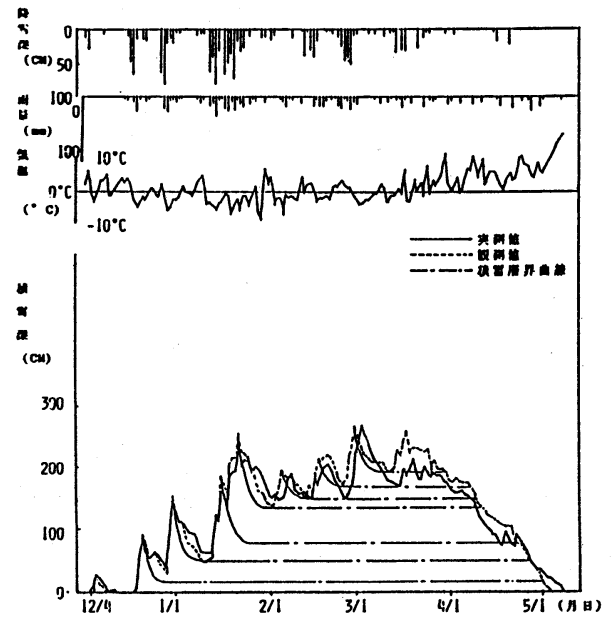

図 -12 積雪深変化図 ( c a s e 1 , 1978 年 12 月 1979 年 6 月)

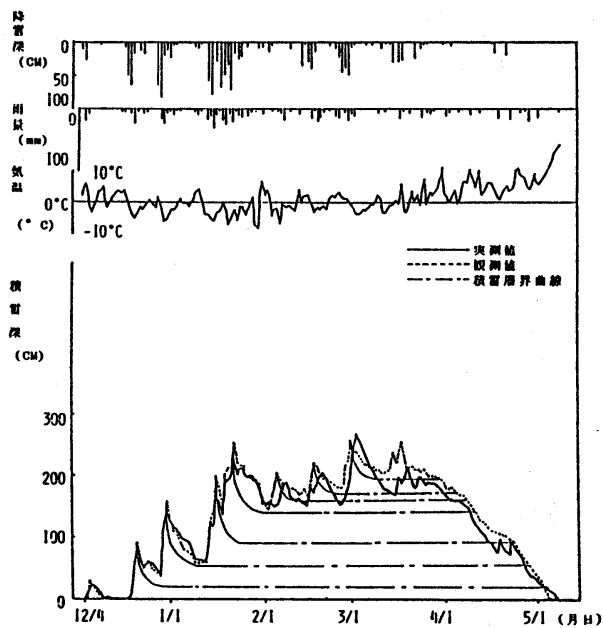

図-13 皘雪深変化図 ( c a s e 2,

1978 年 12 月〜 1979 年 6 月）

解析結果から得られたことを以下に述べる。

(1) 従来の積雪深変化の計算方法では、実測皘雪深と計算値の相関性が鈍いため気温による融雪定数の決定 が定めにくい。

(2) 前報で示した $\mathrm{A} ・ \mathrm{~F} ・ \mathrm{D}$ 型積雪モデルでは、c a s e 1 の場合と考え方は同じであるが、皘雪の圧密効果を 導入していないため積雪深変化の現象をよく表わせなかった。

(3) 積雪の圧密性を考慮した積雪深変化では、実測值と計算値が降雪初期からかなり適合性が良いことが確 認された。この結果、気温日融雪率の值をほほ決定することができ、これにより雪溶日の実測值と計算值と の一致がなされる。

(4) 表 - 1 の結果から、c a s e 1 では、気温日融雪率で 5 m $/$ C・day であり、c a s e 2 では気温日瀜雪率

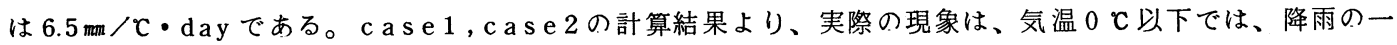


部は流出，浸透し、残りが積雪又は氷凍するのではないかと考えられる。

(5) c a se 2 の考え方では、降雨比重の評価が少し難かしいことから、現時点では c a s e 1 の気温日融雪率 を実用的に用いる方がよいと思われる。

(6)皘雪の圧密性を考慮した皘雪深変化を解析するに当り、皘雪層内の王密過程を示す皘雪層界曲線を作成 した。

\section{4. 結 論}

従来の皘雪計算方法, $\mathrm{A} \cdot \mathrm{F} ・ \mathrm{D}$ 型積雪モデルと $\mathrm{A} ・ \mathrm{~F} ・ \mathrm{D}$ 型積雪モデルに積雪の压密性を導入した皘雪深変 化の解析值と実測值との比較検討結果について述べてきた。これらの結果をまとめて述へると次のょうであ る。

（1）従来の積雪計算方法抽よび $\mathrm{A} ・ \mathrm{~F} ・ \mathrm{D}$ 型積雪モデルに比へて積雪の圧密性を考慮した積雪深変化の計算 方法は、実測積雪哚変化と適合性が非常に良いのが認められた。これより、降雪から積雪・融雪期に打 ける積雪深変化を表わす実用性が十分あると思われる。

(2) 解析結果から、皘雪深変化の融雪期に括いて、気温に打ける融雪定数が融雪に及ぼす影響が非常に大 きいことが確認された。この気温日融雪率の値は、積雪深変化の圧密性を考慮した積雪深変化の計算方法 を用いることにより決定されることが示された。

（3）皘雪深変化の積雪層構成の状態を示す積雪層界曲線を用いることにより、降雪日から皘雪・融雪に至 る時間変化を調べることができた。

（4）今回の研究では、積雪の圧密期間を 10 日と仮定し、压密過程を直線変化として計算を行なったが、 この計算方法に対し、奥只見タム流域以外の流域に対しどのような結果になるかを今後検討していく予 定である。

最後に、本研究の資料を提供して戴いた電源開発(株)、特に同社土木部長代理岡田剛氏に謝意を表します。 また、本研究のデータ作成, 作図に当り東京理科大学土木工学科学生笠間順君, 小島倫範君の協力を得たこ とを記します。

参考文献

1）大西外明, 村上龍一：リモートセンンングを導入した積雪深と融雪洪水流出解析に関する研究， 第 27 回水理講演会論文集, 1983 年

2）電源開発株式会社：奥只見地域，積雪・気象・流量調査資料 